\title{
Response of the turbidity maximum zone to fluctuations in sediment discharge from river to estuary in the Changjiang \\ Estuary (China)
}

\author{
Xuezhong Jiang ${ }^{a, *}$ Bing $\mathrm{Lu}^{\mathrm{a}, \mathrm{b}}$, and Yuhong $\mathrm{He}^{\mathrm{b}}$ \\ a State Key Laboratory of Estuarine and Coastal Research, East China Normal University, \\ Shanghai, 200062, China \\ b Department of Geography, University of Toronto Mississauga, Mississauga, ON, L5L 1C6, \\ Canada
}

\begin{abstract}
In the Changjiang Estuary, interactions between the sea and the river result in the development of a turbidity maximum zone (TMZ). Riverine sediments are an important source for TMZ formation. Since the 1960s, sediment discharge from the river basin to the estuary has decreased due to dam construction, water and soil conservation, and water diversion projects. Thirty-two Landsat images of the estuary, covering the period from 1979 to 2008, were collected to identify the TMZ response to sediment decline. A threshold value of suspended sediment concentration (SSC) of $0.7 \mathrm{~kg} / \mathrm{m}^{3}$, corresponding to a spectrum reflectance of $5 \%$ of Landsat MSS band 7 and $7 \%$ of Landsat TM/ETM band 4, was used to identify the Changjiang Estuary TMZ. The TMZ area was then extracted from each image to investigate its temporal and spatial variations during the past 30 years. The images were grouped into five time series; the average TMZ area of each series was estimated. The results show that the TMZ area declined $23 \%$ from series (a) to series (e), responding to a $77 \%$ reduction in riverine sediment discharge. In addition, the TMZ had strong seasonal and tidal variations; it was generally larger during flood seasons than during dry seasons and during spring tides compared to neap tides. The spring / neap tidal cycle played a more important role in TMZ change than did the seasonal cycle. Due to the continued reduction of sediment discharge to the estuary resulting from dams already constructed and to those that will be constructed upstream in the Changjiang River, it is predicted that the TMZ area will continue decreasing and that the re-suspension of local sediments will play a more important role in the formation of the TMZ.

Keywords: Turbidity Maximum Zone; Sediment Discharge; Landsat Imagery; the Changjiang Estuary; China

\footnotetext{
*Corresponding Author
}

E-mail address: xzjiang@sklec.ecnu.edu.cn

Postal address: State Key Laboratory for Estuarine and Coastal Research, East China Normal University, 3663 N. Zhongshan Rd, Shanghai 200062, P. R. China. Phone: +86+21+62233843 Fax: +86+21+62546441
\end{abstract}




\section{Introduction}

A TMZ is the region in an estuary where the suspended sediment concentration (SSC) is greater than in the surrounding area (Schubel, 1968; Li and Zhang, 1998). The TMZ has been observed and studied in many estuaries, including Gironde Estuary in France (Doxaran et al., 2006), Chesapeake Bay and Hudson Estuary in the USA (Schubel, 1968; Bokuniewicz and Arnold, 1984), St. Lawrence Estuary in Canada (Lucotte and d'Anglejan, 1986), Fly River Estuary in Papua New Guinea (Wolanski and Eagle, 1991), Tamar Estuary in England (Uncles et al., 1985), and Changjiang Estuary in China (Shen et al., 1992). A TMZ is formed by the dynamic accumulation of suspended sediments caused by tidal movements, salinity gradients, estuarine circulation, re-suspension of the bottom sediments, etc. The causes of TMZ formation vary among estuaries and even among different parts of an estuary (Schubel, 1968; Festa and Hansen, 1978; Allen et al., 1980; Eisma, 1986; Uncles and Stephens, 1993; Brenon and Le Hir, 1999). The TMZ plays an important role in the transportation and deposition of fine sediments in estuarine areas and in shaping channel morphology. The TMZ also drives pollutant dispersal patterns by affecting the biogeochemical processing of heavy metals and organic material (Shen et al., 1992; Hollibaugh and Wong, 1999; Gao et al., 2008). As an example, the TMZ strongly affects ocean biological processes because it affects the depth of light penetration into the water column, a factor controlling primary production (May et al., 2003; de Swart et al., 2009). The TMZ also appears to act as an entrapment zone for zooplankton, thus providing a habitat for fish breeding grounds (Dodson et al., 1989; Roman et al., 2001).

The TMZ in the Changjiang Estuary is well developed and is primarily characterised by a high SSC compared with adjacent waters and by a high wash-load content. Tidal movements and saline flow form the TMZ in the Changjiang Estuary, and these two factors have varying influence in different parts of the estuary (Shen et al., 1992). Sediment is supplied to the TMZ from the drainage basin, the sea and estuarine re-suspension, but no research has determined which factor dominates TMZ dynamics.

Studies have come to differing conclusions about the response of estuarine SSC to decreased sediment load. He (2007) compared the temporal and spatial characteristics of SSC during flood seasons in 1982, 2003 and 2005 based on in-situ hydrological and sediment measurements in Changjiang Estuary and adjacent areas. The results indicated that the SSC was reduced during recent flood seasons compared to 1982 , primarily due to decreased sediment flux. In contrast, Jin et al. (2006) observed that estuarine SSC did not decline greatly, based on daily SSC measurements from Aug 1998 to Aug 2001. A possible explanation is that the total amount of movable sediments in the estuarine area is larger than the total quantity of sediment from the river basin because of re-suspension. The average amount of sediment re-suspension was estimated at approximately 3 to 4 billion tons per year, but the annual sediment load from the river basin is only hundreds of millions of tons. 
The influence of decreased sediment on estuarine SSC may not be observed over such a short time.

The inconsistent responses of estuarine SSC to decreased sediment load may result from sparse and infrequent in situ measurements. This may also explain why no in situ study has yet delineated the size of the TMZ, despite the critical importance of this information. A long historical archive of remote sensing data provides an effective means to study the spatial and temporal changes in estuarine areas (Ruhl et al., 2001; Doxaran et al., 2009). Therefore, this study used thirty-two satellite images from 1979 to 2008 to detect TMZ variations in the Changjiang Estuary and to examine the TMZ response to the decrease in sediment load.

\section{Study Area}

The Changjiang River is the longest river in Asia, the fifth largest in the world in terms of water discharge and, historically, the fourth largest in the world in terms of fluvial sediment load (Milliman and Syvitski, 1992; Chen et al., 2001; Stone, 2008). The Changjiang Estuary, located in the centre of the Chinese eastern coast, has a branching channel structure consisting of three bifurcations and four outlets into the East China Sea. The estuary is first divided into the South Branch and the North Branch by Chongming Island. The South Branch is then split into the South Channel and the North Channel by Changxing Island and Hengsha Island. Farther downstream, the South Channel is finally divided into the South Passage and the North Passage by Jiuduansha Wetland. The Changjiang Estuary is a large estuary: the length from the first bifurcation to the mouth bar is approximately $110 \mathrm{~km}$, while the width near the mouth bar is approximately $90 \mathrm{~km}$. The depth varies spatially, from approximately 4 $\mathrm{m}$ to more than $20 \mathrm{~m}$ (Fig. 1).

There is a large annual flux of water and sediment from the Changjiang River basin into the sea. Approximately 50\% of total river sediment is deposited in the estuary each year (Chen et al., 1985). Runoff volume and sediment flux vary seasonally. During the flood season between May and October, the discharge of runoff and sediments was approximately $71.7 \%$ and $87.0 \%$ of the annual amount, respectively (Chen et al., 2001); the rest was discharged in the dry season between November and April. 


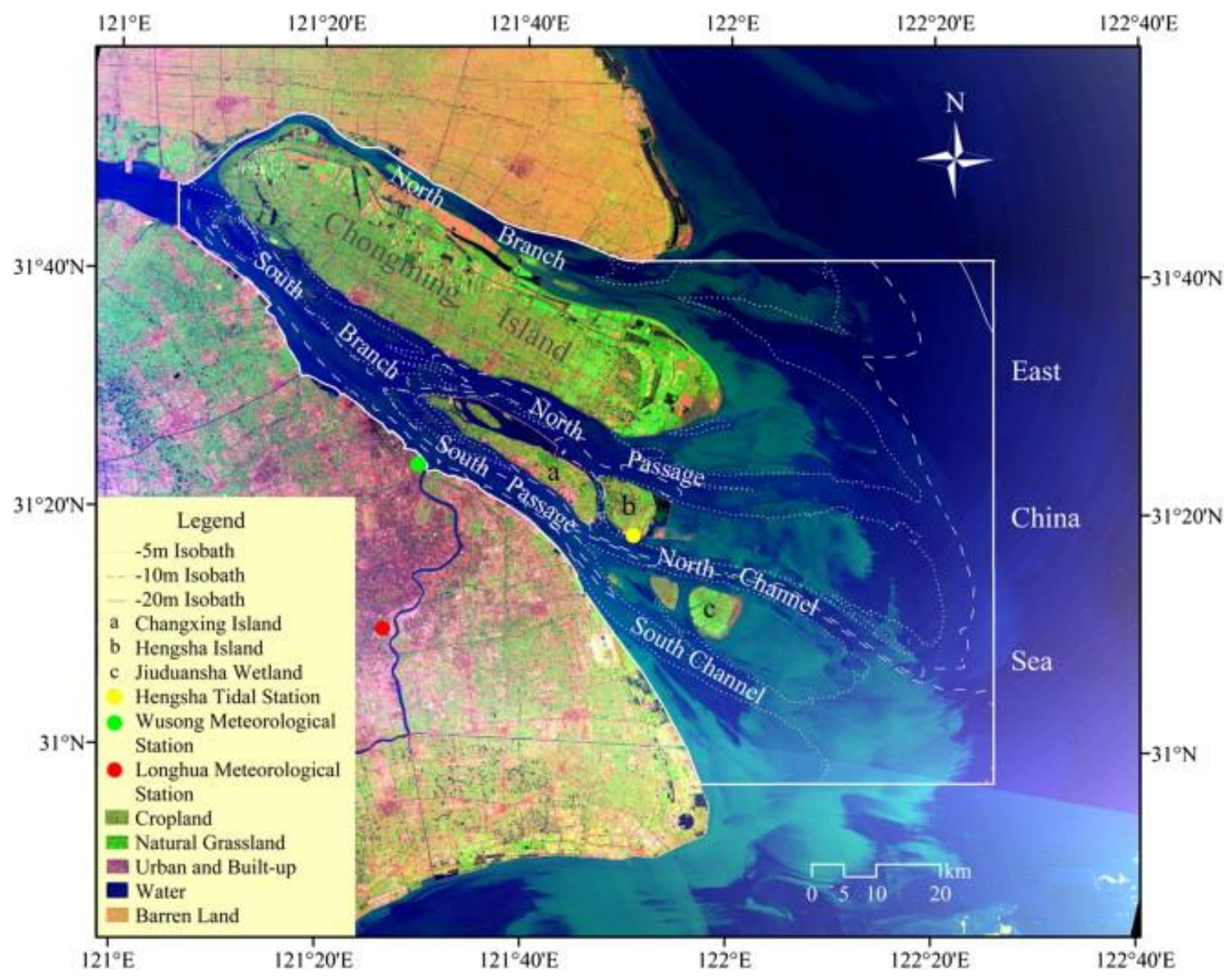

Fig. 1. Landsat ETM image (RGB: band 7, 4 and 2) acquired on 21 Sep 2009 showing the location of the Changjiang Estuary and this study's area of interest (AOI). The overlaid isobaths were digitised from the marine charts published in April 2011 by the Maritime Safety Administration of China.

The Changjiang Estuary is characterised by high turbidity with large spatio-temporal variability. Daily SSC measurements from August 1998 to June 2001 at Hengsha Tidal Station (Fig. 1) showed that the mean SSC value varied from 0.30 $\mathrm{kg} / \mathrm{m}^{3}$ during ebb tide to $0.45 \mathrm{~kg} / \mathrm{m}^{3}$ during flood tide; the maximum value reached 4.2 $\mathrm{kg} / \mathrm{m}^{3}$ (Yun, 2004). The SSC value in the inner estuary is higher in summer than in winter, whereas the SSC value in the outer estuary is lower in summer than in winter. The demarcation line between the inner and the outer estuary is around the upper port of Changxing Island (Chen et al., 2004).

The tidal prism in Changjiang Estuary is large: the spring tidal prism is $5.3 \times 10^{9}$ $\mathrm{m}^{3}$ during flood season and $3.9 \times 10^{9} \mathrm{~m}^{3}$ during dry season, and the neap tidal prism is $1.6 \times 10^{9} \mathrm{~m}^{3}$ during flood season and $1.3 \times 10^{9} \mathrm{~m}^{3}$ during dry season. These tidal prisms are generally greater than the river fluxes in the corresponding periods (Chen et al., 1988). The average tidal range is $2.60 \mathrm{~m}$ at Hengsha Tidal Station. The saline wedge 
(salinity value 5\%) can reach to the middle of Changxing Island near the riverbed at the end of a flood tide (Yun, 2004).

\section{Materials and Methods}

\subsection{Water and Sediment Flux}

The water and sediment flux data from 1965 to 2008 were recorded at Datong Hydrographical Station $\left(30^{\circ} 52^{\prime} \mathrm{N}, 117^{\circ} 44^{\prime} \mathrm{E}\right)$ by the Bureau of Hydrology, Changjiang Water Resources Commission (CWRC). Datong Hydrographical Station is located at the dry season tidal limit of the river mouth; it is the control station for the measurements of water and sediment discharge from the river to the sea. According to the data, no obvious trend was found in the annual water fluxes from the river basin to the estuary from 1965 to 2008 ; the average value over the period was $8.88 \times 10^{11} \mathrm{~m}^{3} / \mathrm{yr}$. However, sediment discharge decreased greatly, the annual sediment discharge to the estuary declined gradually from $5.31 \times 10^{8} \mathrm{~T}$ in 1965 to $0.85 \times 10^{8} \mathrm{~T}$ in 2006 (CMWR, 2006). The average value was $4.53 \times 10^{8} \mathrm{~T} / \mathrm{yr}$ over the first 15 years (from 1965 to 1980), $3.98 \times 10^{8} \mathrm{~T} / \mathrm{yr}$ over the next 14 years (from 1981 to 1995 ) and $2.42 \times 10^{8} \mathrm{~T} / \mathrm{yr}$ over the last 14 years (1996-2008) of the study period (CMWR, 2009).

\subsection{Landsat Imagery Acquisition and Pre-processing}

Thirty-two Landsat images from various sensors were collected for the period from 1979 to 2008 (Table 1). The Landsat series of satellites provides the longest continuous record of satellite-based earth observations; the launch of the first satellite in the series was in 1972 (Chander et al., 2009). The Landsat series consisted of seven satellites from 1972 to 1999; these seven satellites can be grouped into three generations according to their technological capabilities. The first generation included Landsat 1, Landsat 2, and Landsat 3, with the Multispectral Scanner (MSS) sensor. The second generation consisted of Landsat 4 and Landsat 5, which carried the Thematic Mapper (TM) sensor. The third generation included Landsat 6 and Landsat 7, which were equipped with the Enhanced Thematic Mapper (ETM) and the Enhanced Thematic Mapper Plus (ETM+) sensors, respectively. The Landsat data archive at the U.S. Geological Survey Earth Resources Observation and Science Center holds an unequalled 36-year record of the Earth's surface and is available to users via the Internet (Woodcock et al., 2008).

The Landsat images in this study were purchased or downloaded at no cost from the U.S. Geological Survey and the Computer Network Information Centre of the Chinese Academy of Sciences. The images were selected based on availability, quality and coverage of different seasons and tides. The images were grouped into five time series: (a) 1979-1982, (b) 1987-1995, (c) 1997-2001, (d) 2002-2005, and (e) 2006-2008. Each series included a flood season and a dry season, and each season included a spring, a moderate, and a neap tide. Some tides were absent in the dry seasons of series (a) and (b). The tidal information at the mapping moment was referenced to the Hengsha Tidal Station of the local Shanghai Water Authority. The mean wind velocity on the date was recorded by the Wusong Meteorological Station 
and the Longhua Meteorological Station, provided by China Meteorological Data Sharing Service System (http: // cdc.cma.gov.cn) (Fig. 1). The wind velocity was lower than $5.3 \mathrm{~m} / \mathrm{s}$ and the effects of wind and waves on SSC were not considered.

All images were geo-corrected by an image-to-map method referenced to local 1:50000 topographic maps. The radiometric correction of Chander et al. (2009) was followed. Atmospheric correction was based on the dark object subtraction (DOS) method (Chavez, 1996; Song et al., 2001; Lu et al., 2002).

Table 1. Thirty-two Landsat images were collected and grouped into five series from 1979 to 2008 according to different season and tide type.

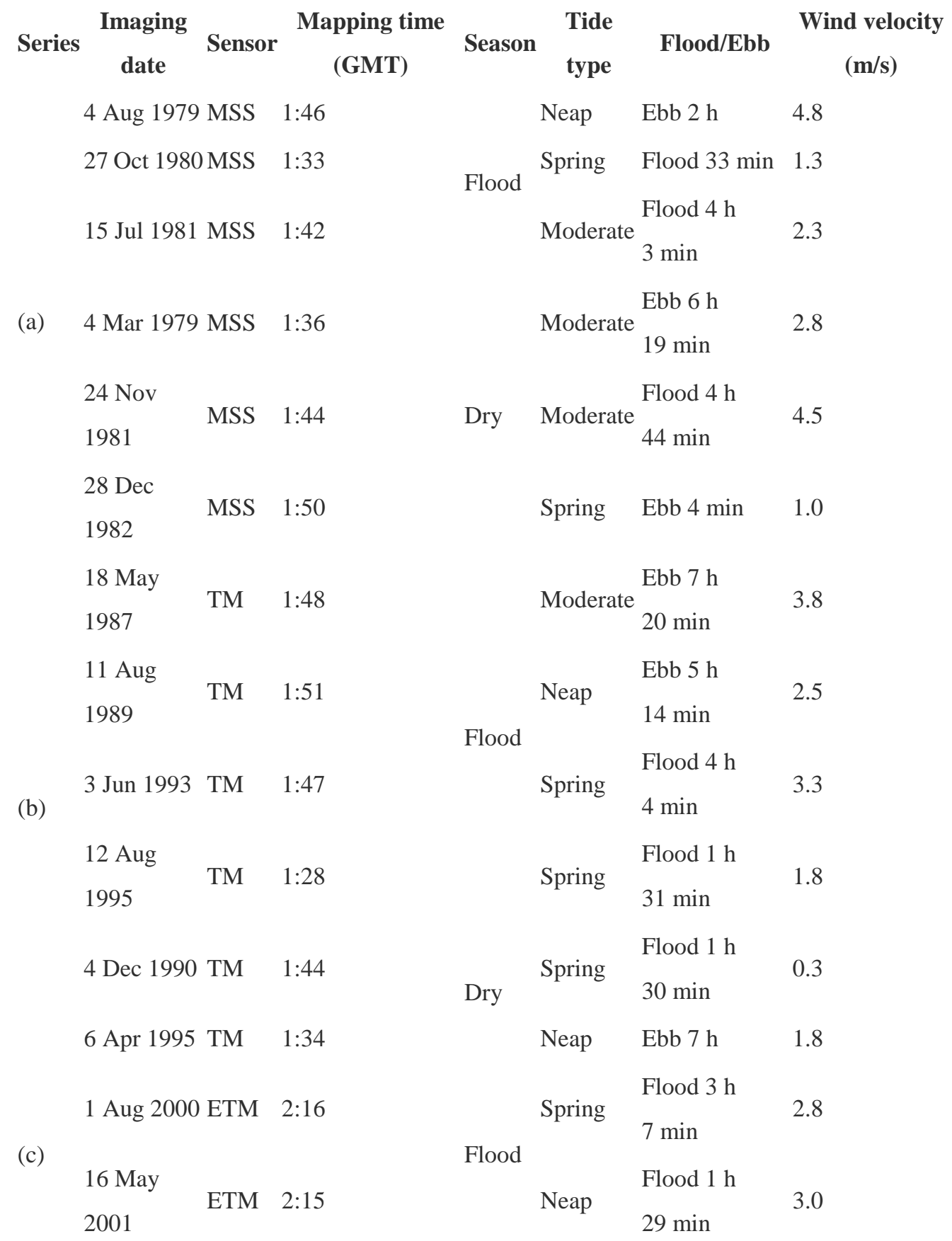




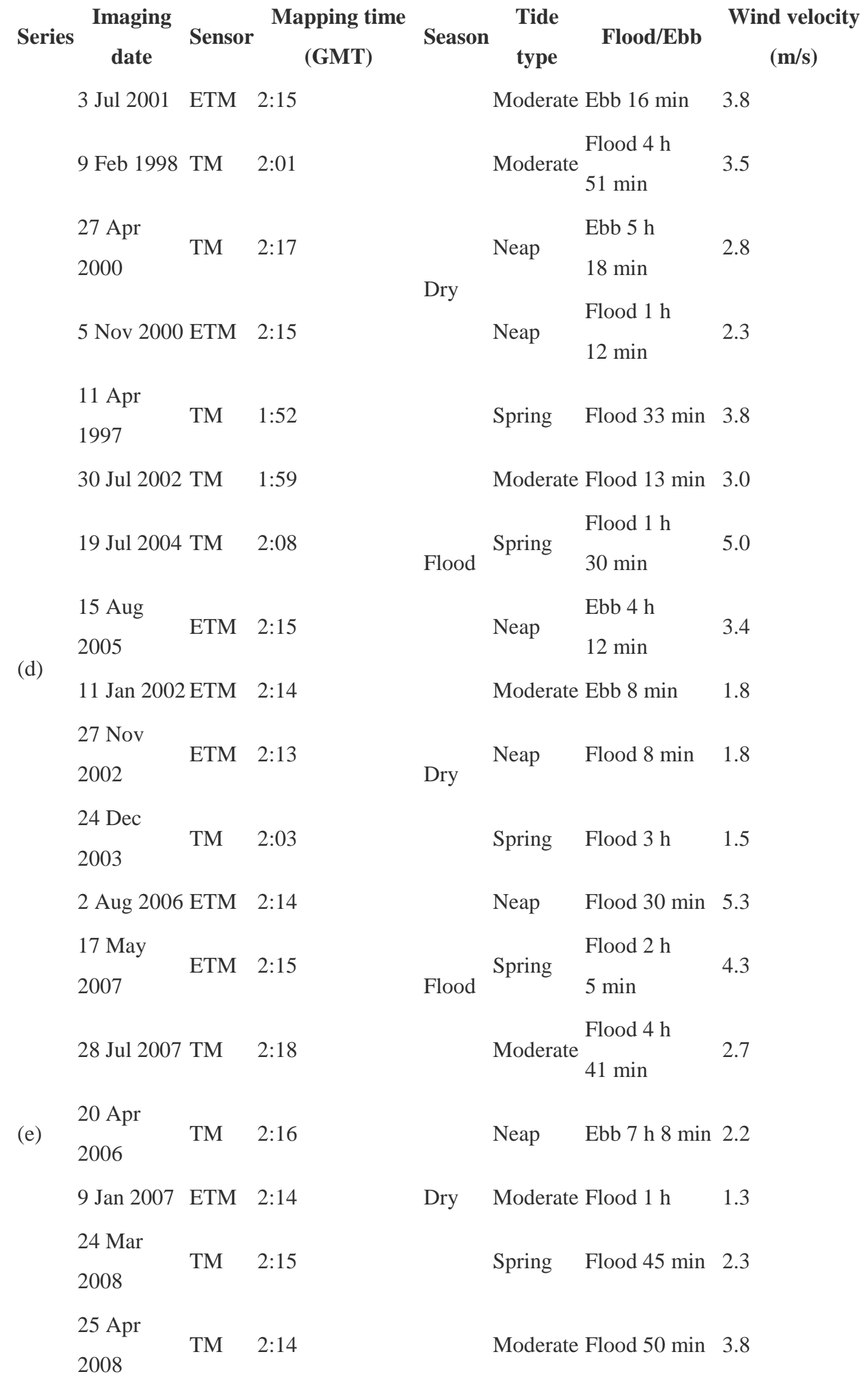

\subsection{The TMZ Area Estimation}

A three-step process was used to estimate TMZ area: 
1) Determining Landsat image bands that are highly correlated with the critical indicator of the TMZ: SSC values. Previous studies of TMZ in the South Passage demonstrated that the reflectance of TMZ water is highly correlated with SSC at the bands of $690 \mathrm{~nm}, 800 \mathrm{~nm}, 810 \mathrm{~nm}$ and $860 \mathrm{~nm}$ (Jiang et al., 2011). In addition, the Landsat MSS band 7 (central wavelength approximately $900 \mathrm{~nm}$ ) and TM/ETM band 4 (central wavelength approximately $840 \mathrm{~nm}$ ) have also been shown to have a high correlation with SSC (Ritchie and Cooper, 1988; Ritchie et al., 1990). Therefore, the reflectance of these two bands was chosen to delineate the TMZ.

2) Defining the critical surface $S S C$ value that can be used to separate the TMZ from the surroundings. Previous studies have no specific value as the critical SSC value for the TMZ in the Changjiang Estuary. In this study, based on the range of surface SSC values in the TMZ (from $0.1 \mathrm{~kg} / \mathrm{m}^{3}$ to $4.2 \mathrm{~kg} / \mathrm{m}^{3}$ (Yun, 2004)) as well as SSC measurements in different parts of the Changjiang Estuary (Li and Zhang, 1998), an SSC value higher than $0.7 \mathrm{~kg} / \mathrm{m}^{3}$ was empirically used to indicate the TMZ.

3) Determining the critical reflectance values for MSS band 7 and for TM/ETM band 4 to delineate the TMZ with a SSC value higher than $0.7 \mathrm{~kg} / \mathrm{m}^{3}$. In situ measurements were taken in the Changjiang Estuary during 9 Aug 1978 (Yun, 2004) and 24 Mar 2008 (Jiang et al., 2011). Water samples were collected and transported back to the laboratory to calculate the SSC. Landsat images were available at these two times, from the MSS and TM sensors, respectively. In comparing the reflectance values with the synchronous field-measured SSC, we observed that an SSC value of approximately $0.7 \mathrm{~kg} / \mathrm{m}^{3}$ corresponded with a MSS band 7 reflectance values of approximately 5\% and a TM/ETM band 4 reflectance values of approximately $7 \%$. Higher SSC values corresponded to higher reflectance values between bands $350 \mathrm{~nm}$ and $950 \mathrm{~nm}$, thus reflectance values greater than 5\% in MSS band 7 and greater than 7\% in TM/ETM band 4 were used to delineate the region where SSC was higher than 0.7 $\mathrm{kg} / \mathrm{m}^{3}$; this region was regarded as the TMZ. The area of the TMZ inside the AOI polygon (Fig. 1) was then calculated for each image, and the average value of each time series was used to determine the changes during the past 30 years.

The ENVI software from American ITT Visual Information Solutions Company and ArcGIS from American Environmental Systems Research Institute, Inc. (ESRI) were used for the above processing.

\section{Results and Discussion}

\subsection{The TMZ Delineation Results}

The TMZ area for each image was calculated, the area value varied dramatically from a minimum area of $987 \mathrm{~km}^{2}$ (on 24 Nov 1981) to a maximum area of $2639 \mathrm{~km}^{2}$ (on 4 Dec 1990), with an average area of $1570 \mathrm{~km}^{2}$.The results extracted from images of spring/neap tide in the flood and dry seasons are shown in Fig. 2. The typical location of the TMZ was in the North Branch and along the mouth bar areas near the eastern edges of Chongming and Hengsha Islands, the surrounding regions of Jiuduansha Wetland. The mechanisms of formation differ for different parts of the 
TMZ. The TMZ in the North Branch and South Passage is mainly formed by tidal action. The TMZ in the North Channel and North Passage, the main river channels, is mainly formed by residual circulation caused by saline flow (Shen et al., 1992).
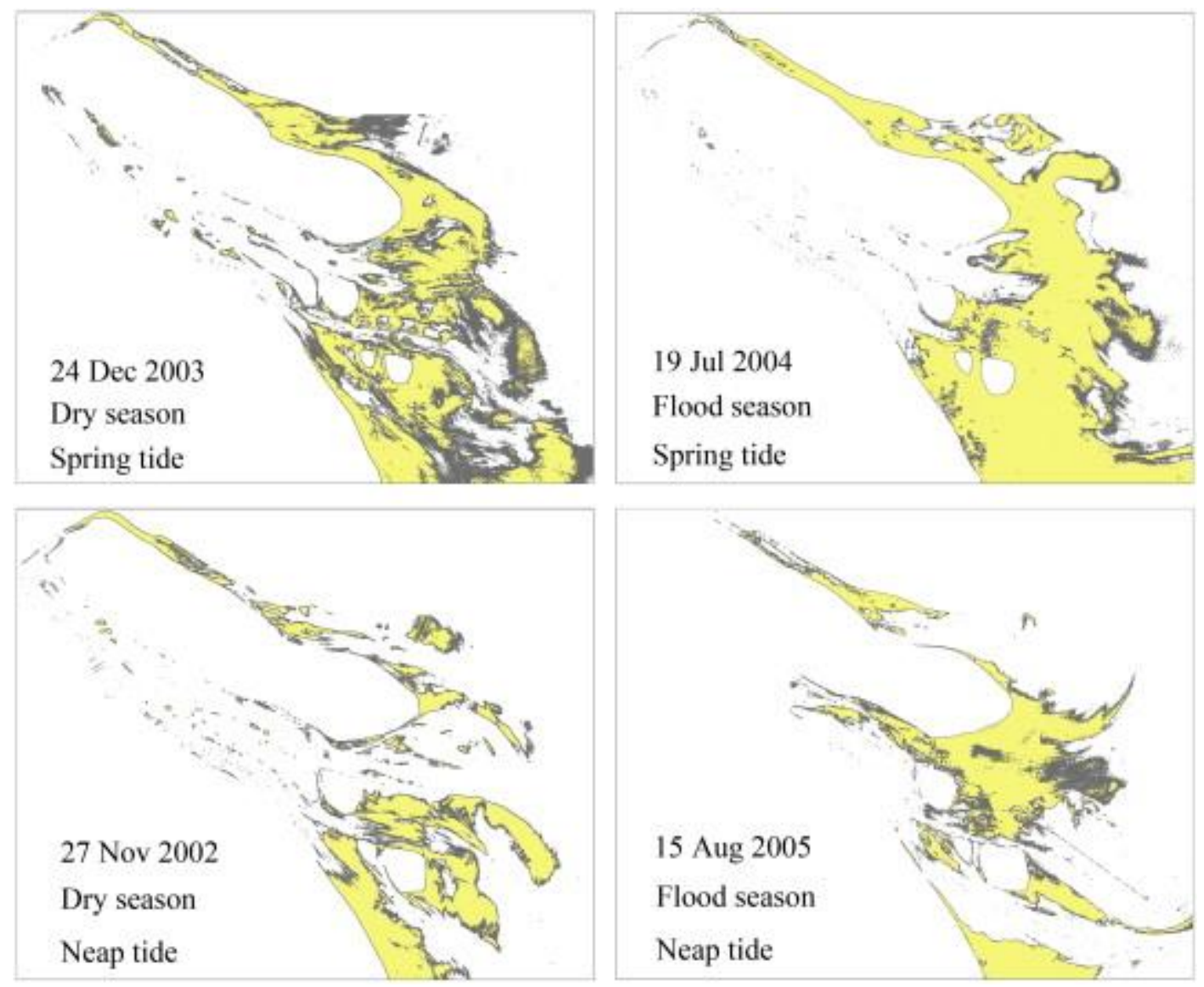

Fig. 2. The TMZ extraction results, generally the area was larger in spring tide than in neap.

\subsection{Variations in $T M Z$ Areas}

The difference in TMZ area between high discharge and low discharge seasons was also analysed (Fig. 2 and Table 2). The mean TMZ area is $1567 \mathrm{~km}^{2}$ in the flood season and $1547 \mathrm{~km}^{2}$ in the dry season. This is because sediment flow to the estuary is greater during the flood season and thus is a larger sediment source to the TMZ. This is confirmed by previous studies, which indicate that the flood season TMZ is larger than that in the dry season ( $\mathrm{Li}$ and Zhang, 1998). However, the differences in average TMZ area between the dry season and the flood season are not dramatic. The enhanced tidal current caused by strong winter storms, which leads to intensive re-suspension during the dry season, may be a possible explanation (Gao et al., 2008).

The differences in TMZ areas among spring, moderate and neap tides are also shown in Table 2. The spring tide has much stronger effects on the TMZ than the neap 
tide, corresponding to $2062 \mathrm{~km}^{2}$ and $1328 \mathrm{~km}^{2}$ in the flood season and $1962 \mathrm{~km}^{2}$ and $1219 \mathrm{~km}^{2}$ in the dry season, respectively. This result is consistent with other studies, in which the TMZ was observed to increase in area more during the spring tide than during the neap tide ( $\mathrm{Li}$ and Zhang, 1998). The dramatic area difference between the spring and neap tides can be explained by greater re-suspension during spring tides.

The tidal phase contributed more to variation in $\mathrm{TMZ}$ area than did the season of the year. A similar conclusion can be drawn from the field-acquired SSC statistics of different locations: in the mouth bar area, the difference in average SSC between the flood and dry seasons is less than $0.18 \mathrm{~kg} / \mathrm{m}^{3}$, but it is greater than $0.32 \mathrm{~kg} / \mathrm{m}^{3}$ between the spring and neap tide ( $\mathrm{Li}$ and Zhang, 1998).

Table 2. The TMZ area variations among different tides in the flood season and the dry season $(\mathrm{km} 2)$.

Spring tide Moderate tide Neap tide Mean

$\begin{array}{lllll}\text { Flood Season 2062 } & 1310 & 1328 & 1567 \\ \text { Dry Season } & 1962 & 1462 & 1219 & 1547\end{array}$

\subsection{The Distribution Change of TMZ}

The decreased sediment flux from the river basin to the estuary also led to changes in the TMZ distributions, especially during the flood season. Comparing the flood season TMZ distribution under similar tidal conditions, we observed that the TMZ has moved seaward. In the earlier years, for example on 12 Aug 1995 and 15 Jul 1981, the TMZ was mostly in the inner estuary and the mouth bar area during flood seasons; In contrast, in flood seasons of later years, on 19 Jul 2004 and 28 Jul 2007, the TMZ region was mostly in the mouth bar area and the outer estuary (Fig. 3). The upper limit of the TMZ moved from upstream of Changxing Island to downstream of Hengsha Island; the lower limit moved seaward, but the change was not as great as that for the upper limit. These results indicated that the seaward shift of the upper limit of the TMZ is most likely the result of decreased sediment flux. The TMZ distribution was less variable among dry seasons than among flood seasons. The decrease of sediment flux likely had less influence on the TMZ in the dry seasons because the sediment source of the TMZ was mainly from local and adjacent areas during dry seasons. 

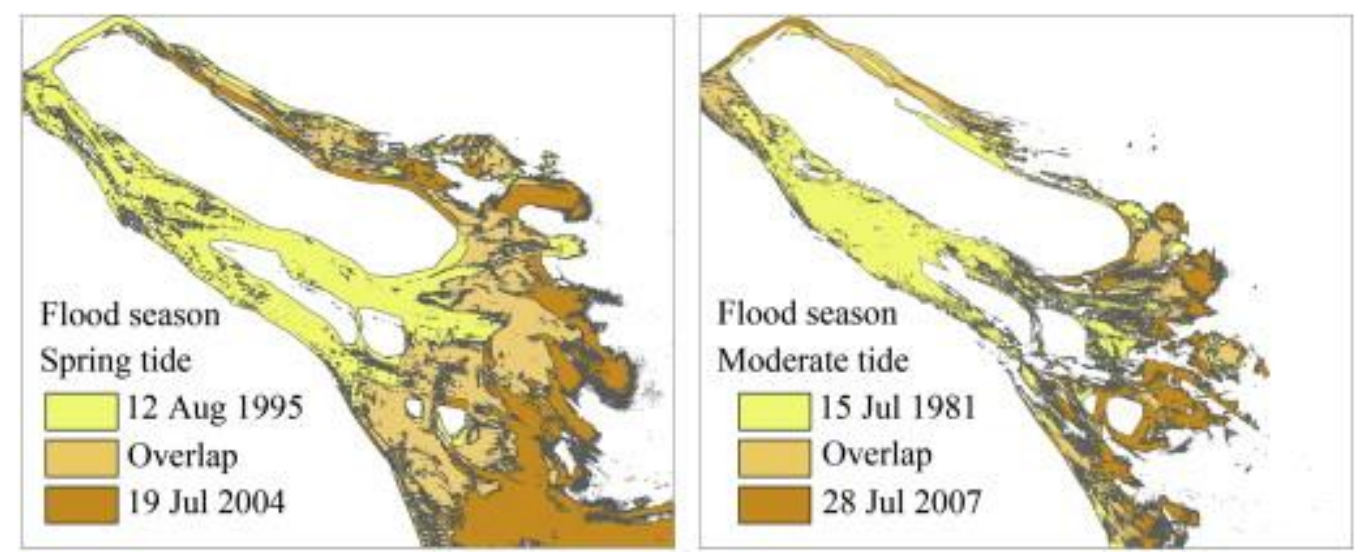

Fig. 3. The distribution of the TMZ changed in the past decades.

The TMZ was observed to vary according to an interactive effect of the river flow and tidal currents. The general upper limit of the TMZ could reach approximately $121^{\circ} 20^{\prime} \mathrm{E}$ (upstream of the Changxing Island). The general lower limit of the TMZ was reaching $122^{\circ} 15^{\prime} \mathrm{E}$, while the lowest limit was near $122^{\circ} 33^{\prime} \mathrm{E}$. The general range between the upper and lower limit was about $95 \mathrm{~km}$, greater than the TMZ range of either the Gironde Estuary (approximately $70 \mathrm{~km}$ ) (Doxaran et al., 2006) or the Chesapeake Bay (approximately $40 \mathrm{~km}$ ) (Sanford et al., 2001). The distribution of the TMZ showed strong seasonal and tidal variations.

\subsection{The Response of TMZ to the Sediment Decrease}

The sediment discharge from the Changjiang River basin to the estuary has decreased greatly since the $1960 \mathrm{~s}$, primarily due to dam construction. In the past 50 years, more than 10,000 dams have been built in the drainage basin, including the Three Gorges Dam, trapping large amounts of sediment in reservoirs (Yang et al., 2005; Zhang et al., 2006). Decreasing sediment discharge has led to changes in the estuary. The TMZ area and its distribution change have shown the response to the sediment decrease. The average TMZ area of each time series decreased gradually as the sediment flux declined, there were $1848 \mathrm{~km}^{2}, 1554 \mathrm{~km}^{2}, 1586 \mathrm{~km}^{2}, 1456 \mathrm{~km}^{2}$ and $1428 \mathrm{~km}^{2}$, corresponding to series (a), (b), (c), (d) and (e), respectively (Fig. 4). The lower sediment discharge from the Changjiang River basin led to the reduction of the TMZ area and seaward shift of the upper limit of the TMZ in the estuary. However, the decline in average area was not as great as the decline in sediment flux. A possible explanation is that the TMZ depends upon sediments not only from the river basin but also from local sediments exchanged within the estuary and from adjacent waters. Thousands of years of sediments have been deposited in these areas, similar to a sediment reservoir (Liu et al., 2010), and these may provide sediment for the formation of the TMZ. The diminution of TMZ area was verified by the suspended sediment concentration measurements, which showed a 20-30\% decrease in the lower estuary and adjacent coastal waters over the past 10-20 years ( $\mathrm{Li}, 2012)$. 


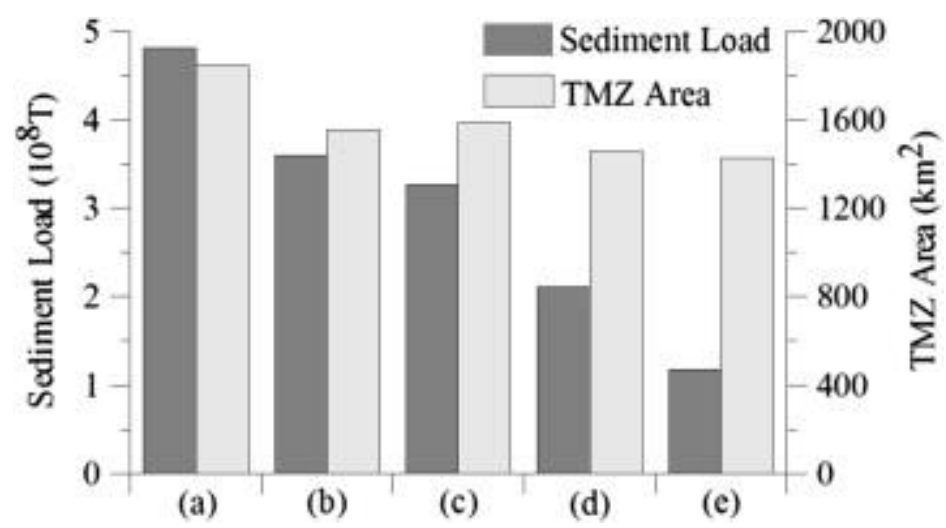

Fig. 4. Sediment loads and TMZ areas in the five periods. The sediment loads were averaged for each time series.

The TMZ areas are predicted to continue declining and to reach a new equilibrium eventually. Local sediment sources will play a more important role in the TMZ, as there will be less river-derived sediment in the estuary due to new project construction in the Changjiang river basin (Yang et al., 2003; Yang et al., 2006).

\section{Conclusions}

Thirty-two Landsat images from 1979 to 2008 were collected to examine the response of the TMZ to a decrease of sediment load and to study the TMZ variations within the Changjiang Estuary. The TMZ area for each image was calculated. When we grouped the images into five series according to different reasons and tide type, the average area value of each time series showed the trend of the TMZ changes and led to the following conclusions:

a. From series (a) to series (e), the $\mathrm{TMZ}$ areas declined about $23 \%$ in response to a $77 \%$ reduction in sediment discharge from the Changjiang River basin to the estuary.

b. Local sediment was an important source for the TMZ in the well-mixed Changjiang Estuary, which caused the reduction of the TMZ area to be less than the reduction of riverine sediment flux.

c. The large variation in $\mathrm{TMZ}$ area was related to the season of the year and tidal stage. The spring / neap tidal cycle is a stronger determinant of TMZ area and spatial distribution than the seasonal cycle. In general, the TMZ was larger during flood seasons than during dry seasons and during spring tides compared to neap tides.

d. During the last 30 years, the TMZ decreases were mainly in the inner portion of the estuary. The changes outside the river mouth were not as great because of strong local sediment re-suspension.

e. A continued decrease in sediments from the river basin will likely cause a further 
decline in the TMZ area. Local sediment supply will play a more important role in TMZ formation.

\section{Acknowledgements}

This study was jointly funded by the key project of Natural Science Foundation of China (41130856), the key project of Shanghai Municipal Science and Technology Commission (12231203100) and the SKLEC grant program (No.

SKLEC-2012KYYW02). Thanks should be extended to Michael Preston, Kelly Wong and the anonymous reviewers for their invaluable and constructive suggestions, which greatly improved the quality of the paper.

\section{References}

Allen, G. P., Salomon, J. C., Bassoullet, P., Du Penhoat, Y., de Grandpr, C., 1980. Effects of tides on mixing and suspended sediment transport in macrotidal estuaries. Sedimentary Geology 26, 69-90.

Bokuniewicz, H., Arnold, C. L., 1984. Characteristics of suspended sediment transport in the lower Hudson River. Northeastern Environmental Science 3, 185-190.

Brenon, I., Le Hir, P., 1999. Modelling the Turbidity Maximum in the Seine Estuary (France): Identification of Formation Processes. Estuarine, Coastal and Shelf Science 49, 525-544.

Chander, G., Markham, B. L., Helder, D. L., 2009. Summary of current radiometric calibration coefficients for Landsat MSS, TM, ETM+, and EO-1 ALI sensors. Remote Sensing of Environment 113, 893-903.

Chavez, P. S., 1996. Image-based atmospheric corrections : revisited and improved. Photogrammetric engineering and remote sensing 62, 1025-1036.

Chen, J. Y., Zhu, H. F., Dong, Y. F., Sun, J. M., 1985. Development of the Changjiang estuary and its submerged delta. Continental Shelf Research 4, 47-56.

Chen, J. Y., Shen, H. T., Yun, C. X., 1988. The dynamical process and physiognomy evolvement in the Yangtze River. Shanghai Science and Technology Press, Shanghai, 454 pp. (in Chinese)

Chen, S. L., Zhang, G. A., Yang, S. L., Yu, Z. Y., 2004. Temporal and spatial changes of suspended sediment concentration and re-suspension in the Yangtze River Estuary and its adjacent waters. Acta Geographica Sinica 59, 260-266. (in Chinese, with English Abstract)

Chen, Z. Y., Li, J. F., Shen, H. T., Wang, Z. H., 2001. Yangtze River of China: historical analysis of discharge variability and sediment flux. Geomorphology 41, 77-91.

CMWR, 2006. China Ministry of Water Resources. Chinese River Sediment Bulletin. China Waterpower Press, Beijing, 68 pp. (in Chinese)

CMWR, 2009. China Ministry of Water Resources. Chinese River Sediment Bulletin. China Waterpower Press, Beijing, 70 pp. (in Chinese) 
de Swart, H.E., Schuttelaars, H.M., Talke, S.A., 2009, Initial growth of phytoplankton in turbid estuaries: a simple model. Continental Shelf Research 29, 136-147.

Dodson, J.J., Dauvin, J., Ingram, R., D Anglejan, B., 1989, Abundance of larval rainbow smelt (Osmerus mordax) in relation to the maximum turbidity zone and associated macroplanktonic fauna of the middle St. Lawrence estuary. Estuaries and Coasts 2, 66-81.

Doxaran, D., Castaing, P., Lavender, S. J., 2006. Monitoring the maximum turbidity zone and detecting fine-scale turbidity features in the Gironde estuary using high spatial resolution satellite sensor (SPOT HRV, Landsat ETM+) data.

International Journal of Remote Sensing 27, 2303-2321.

Doxaran, D., Froidefond, J., Castaing, P., Babin, M., 2009. Dynamics of the turbidity maximum zone in a macrotidal estuary (the Gironde, France): Observations from field and MODIS satellite data. Estuarine, Coastal and Shelf Science 81, 321-332.

Eisma, D., 1986. Flocculation and de-flocculation of suspended matter in estuaries. Netherlands Journal of Sea Research 20, 183-199.

Festa, J. F., Hansen, D. V., 1978. Turbidity maxima in partially mixed estuaries: A two-dimensional numerical model. Estuarine and Coastal Marine Science 7, 347-359.

Gao, J. H., Yang, Y., Wang, Y. P., Pan, S. M., Zhang, R. 2008, Sediment dynamics of turbidity maximum in Changjiang River mouth in dry season. Frontiers of Earth Science in China 3, 249-261.

He C., 2007. Study of suspended sediment distribution's status quo and recent 20 year's comparison in the Yangtze Estuary and adjacent sea area. Master Thesis, East Normal University, Shanghai, China, unpublished. (in Chinese, with English Abstract)

Hollibaugh, J.T., Wong, P.S., 1999. Microbial processes in the San Francisco Bay estuarine turbidity maximum. Estuaries and Coasts 22, 848-862.

Jiang, X. Z., Cheng, J., Guo, X. L., 2011. The flocculation of fine-grained suspended sediment and its impact on spectral characteristics based on in situ measurement in the Changjiang Estuary, China. Canadian Journal of Remote Sensing 37, 404-412.

Jin, L., Yu, Z. Y., He, Q., 2006. On the relationship between maintenance condition of Yangtze Estuary Deepwater Channel and water \& sediment transport from the valley. Ports \& Waterway Engineering 3, 46-51. (in Chinese, with English Abstract)

Li J. F., Zhang, C., 1998. Sediment re-suspension and implications for turbidity maximum in the Changjiang Estuary. Marine Geology 148, 117-124.

Li P., Yang S.L., Milliman J.D., Xu K.H., Qin W.H., Wu C.S., Chen Y.P., Shi B.W., 2012. Spatial, temporal, and human-induced variations in suspended sediment concentration in the surface waters of the Yangtze Estuary and adjacent coastal areas. Estuaries and Coasts 35, 1316-1327.

Liu H, He Q, Wang Z., Gert Jan Weltje, Zhang J., 2010. Dynamics and spatial variability of near-bottom sediment exchange in the Yangtze Estuary, China. Estuarine, Coastal and Shelf Science 86, 322-330. 
Lu, D., Mausel, P., Brondizio, E., Moran, E., 2002. Assessment of atmospheric correction methods for Landsat TM data applicable to Amazon basin LBA research. International Journal of Remote Sensing 23, 2651-2671.

Lucotte, M., d'Anglejan, B., 1986, Seasonal control of the Saint-Lawrence maximum turbidity zone by tidal-flat sedimentation. Estuaries and Coasts 2, 84-94.

May, C.L., Koseff, J.R., Lucas, L.V., Cloern, J.E., Schoellhamer, D.H., 2003. Effects of spatial and temporal variability of turbidity on phytoplankton blooms. Marine Ecology Progress Series 254, 111-128.

Milliman, J. D., Syvitski, J. P. M., 1992. Geomorphic/tectonic control of sediment discharge to the ocean: The importance of small mountainous rivers. Journal of Geology 100, 525-544.

Ritchie, J. C., Cooper, C. M., 1988. Comparison of measured suspended sediment concentrations with suspended sediment concentrations estimated from Landsat MSS data. International Journal of Remote Sensing 9, 379-387.

Ritchie, J. C., Cooper, C. M., Schiebe, F. R., 1990. The relationship of MSS and TM digital data with suspended sediments, chlorophyll, and temperature in Moon Lake, Mississippi. Remote Sensing of Environment 33, 137-148.

Roman, M. R., Holliday, D. V. Sanford, L. P., 2001. Temporal and spatial patterns of zooplankton in the Chesapeake Bay turbidity maximum. Marine Ecology Progress Series 213, 215-227.

Ruhl, C. A., Schoellhamer, D. H., Stumpf, R. P., Lindsay, C. L., 2001. Combined use of remote sensing and continuous monitoring to analyse the variability of suspended-sediment concentrations in San Francisco Bay, California. Estuarine, Coastal and Shelf Science 53, 801-812.

Sanford, L., Suttles, S., Halka, J., 2001. Reconsidering the physics of the Chesapeake Bay estuarine turbidity maximum. Estuaries and Coasts 24, 655-669.

Schubel, J. R., 1968. Turbidity maximum of the northern Chesapeake Bay. Science. 161, 1013-1015.

Shen, H. T., He, S. L., Pan, D. A., Li, J. F., 1992. A study of turbidity maximum in the Changjiang Estuary. Acta Geographica Sinica 47,472-479. (in Chinese with English Abstract)

Song, C., Woodcock, C. E., Seto, K. C., Lenney, M. P., Macomber, S. A., 2001. Classification and change detection using Landsat TM data:: When and how to correct atmospheric effects? Remote Sensing of Environment 75, 230-244.

Stone, R., 2008. Three Gorges Dam: Into the unknown. Science 321, 628-632.

Uncles, R. J., Elliott, R. C. A., Weston, S. A., 1985. Observed fluxes of water, salt and suspended sediment in a partly mixed estuary. Estuarine, Coastal and Shelf Science 20, 147-167.

Uncles, R. J., Stephens, J. A., 1993. The freshwater-saltwater interface and its relationship to the turbidity maximum in the Tamar Estuary, United Kingdom. Estuaries and Coasts 16,126.

Wolanski, E., Eagle, M., 1991. Oceanography and fine sediment transport, Fly River Estuary and Gulf of Papua. Water Quality Centre publication. Hamilton, New Zealand: Water Quality Centre, DSIR Marine and Freshwater, pp: 428-432. 
Woodcock, C. E., Allen, A. A., Anderson, M., Belward, A. S., Bindschadler, R., Cohen, W. B., Gao, F., Goward, S. N., Helder, D., Helmer, E., Nemani, R., Oreapoulos, L., Schott, J., Thenkabail, P. S., Vermote, E. F., Vogelmann, J., Wulder, M. A., \& Wynne, R., 2008. Free access to Landsat imagery. Science 320, 1011.

Yang, S. L., Belkin, I. M., Belkina, A. I., Zhao, Q. Y., Zhu, J., Ding, P. X., 2003.

Delta response to decline in sediment supply from the Yangtze River: evidence of the recent four decades and expectations for the next half-century. Estuarine, Coastal and Shelf Science 57, 689-699.

Yang, S. L., Zhang, J., Zhu, J., Smith, J. P., Dai, S. B., Gao, A., Li, P., 2005. Impact of dams on Yangtze River sediment supply to the sea and delta intertidal wetland response. Journal of Geophysical Research. 110, F03006, doi:10.1029/2004JF000271.

Yang, Z., Wang, H., Saito, Y., Milliman, J. D., Xu, K., Qiao, S., Shi, G., 2006. Dam impacts on the Changjiang (Yangtze) River sediment discharge to the sea: The past 55 years and after the Three Gorges Dam. Water Resources Research 42,W4407, doi:10.1029/2005WR003970.

Yun, C. X., 2004. The recent development rules of the Yangtze Estuary. China Ocean Press, Beijing, 290 pp. (in Chinese with English Abstract)

Zhang, Q., Xu, C., Becker, S., Jiang, T., 2006. Sediment and runoff changes in the Yangtze River basin during past 50 years. Journal of Hydrology 331, 511-523. 